\section{Persistent Sciatic Artery Presenting with Right Lower Limb Ischemia: A Potential Sonographic Pitfall}

\section{Vinay Venkatesh, Girish Doddabasappa and Venkatraman Bhat* $^{*}$}

Department of Radiology, Narayana Health, Bengaluru, India

\begin{abstract}
A case of persistent sciatic artery is reported in a patient with the lower limb ischaemia. Initial imaging dopplar sonography suggested a possible occlusion of the superficial femoral artery. Computed tomographic angiography, however, demonstrated presence of bilateral persistence sciatic arteries in association with aneurysms. Repeat sonography demonstrated anatomical variation and the aneurysm. Experience from this illustration proposes modification of Doppler ultrasound technique based on cluster of observation in a clinical setting, to include wider areas of sonographic scrutiny. A brief review of embryology, imaging appearance, classification and management strategy of persistent sciatic artery is presented.
\end{abstract}

Keywords: CTA; Dopplar sonography; Embryology of lower limb arteries; Persistant sciatic artery; Sciatic artery aneurysm

\section{Introduction}

A persistent sciatic artery is a rare vascular anomaly [1-4] where there is continuation of the internal-iliac-artery into the thigh through the greater sciatic notch into the lower extremity. Unlike the fully developed native femoral-arteries, persistent-sciatic-arteries are prone to develop early atheromatous degeneration and formation of an aneurysm. Hypoplasia of the elastic components and the primitive composition of the arterial wall may be one of the caustive factor. The thrombosis of the aneurysm, resultant distal micro emboli

*Corresponding author: Venkatraman Bhat, Department of Radiology, Narayana Health, 309, Greenwoods Apt. Bommasandra, Bengaluru, India; Tel: +91 9481027387; E-mail: bvenkatraman@gmail.com

Citation: Venkatesh V, Doddabasappa G, Bhat V (2020) Persistent Sciatic Artery Presenting with Right Lower Limb Ischemia: A Potential Sonographic Pitfall. J Non Invasive Vasc Invest 5: 027.

Received: December 24, 2020; Accepted: December 29, 2020; Published: December 31, 2020

Copyright: ( 2020 Venkatesh V, et al. This is an open-access article distributed under the terms of the Creative Commons Attribution License, which permits unrestricted use, distribution, and reproduction in any medium, provided the original author and source are credited. and ischemic changes in the lower limb, is one of the known manifestation. Doppler examination of the lower limb is a common examination for suspected limb ischemia. Usual protocols do not take in to consideration for all possible anatomical variations, especially rare ones. It is important to look for subtle indirect signs of likely developmental variations when performing lower limb vascular examinations. We report a case of persistent sciatic artery which evaded the sonographic diagnosis initially. Managment of the patient, however was done with Computed Tomography Angiography (CTA) and repeat sonography.

\section{Clinical Presentation}

A 50-year-old female presented with intermittent pain and numbness in right lower limb for the past 2 months. She had normal blood pressure measurements; her laboratory investigations were normal. She had dusky bluish colouration of right distal leg and foot. Peripheral pulses were normal in upper limbs and left lower limb. Right dorsalis-pedis and posterior-tibial pulsations were feeble. She underwent Doppler ultrasound of lower extremities, which revealed triphasic flow in right External-Iliac-Artery (EIA), Common-Femopral-Artery (CFA) and proxinal Superficial Femoral Artery (SFA). Monophasic flow was noted in the right distal SFA, which appeared small in caliber. The flow in the popliteal-artery and Posterior-Tibial-Artery (PTA) were biphasic. There was feeble flow signals detected in Anterior-Tibial-Artery (ATA) and dorsalis pedis arteries. Examination of the left lower limb was normal. Findings were consistent with a possible occlusion of mid-distal SFA. No thrombus was identified in any of the visualised vessels. Patient underwent Computed Tomography Angiogram (CTA) for more detailed vascular anatomy. Examination showed the bilateral persistent sciatic continuation of the internal-iliac-arteries in association with two aneurysms in the right gluteal region (Figure 1). Structure and contours of the arteries and aneurysm were better demonstrated in 3D reconstruction (Figure 2). Distally right poplitealartery was reformatted by the sciatic-artery as demonstrated in the delayed arterial phase indicating slow flow in these vessels. The PTA showed good contrast opacification. The ATA and dorsalis pedis were small, faintly reconstituted in the delayed phase, confirming the partial vascular occlusion. On performing a repeat color Doppler ultrasound examination, with diagnosis in mind, the persistent-sciaticartery and aneurysm were visualsed in the gluteal region (Figure 3). The right sciatic nerve was also identified close to the artery. Surgical management was recommended to the patient. Patient deffered surgery in preference to conservative medical management.

\section{Discussion}

Persistent Sciatic Artery (PSA) refers to the persistence of the embryonic sciatic artery. It is the result of incomplete or in some cases absolute non-obliteration of the Sciatic-Artery (SA) during developmental process [1]. Developmentally SA originate from the Umbilical-Arteries (UA) at approximately the 6-mm embryonic stage and serve as the primitive blood supply to the developing lower limb-bud. As development resumes the SA extends in the caudal 
Citation: Venkatesh V, Doddabasappa G, Bhat V (2020) Persistent Sciatic Artery Presenting with Right Lower Limb Ischemia: A Potential Sonographic Pitfall. J Non Invasive Vasc Invest 5: 027.

direction along the dorsal aspect of the skeletal mesenchyme where it terminates at the foot. The EIA, which replaces the SA, originates from the UA just proximal to the SA. At the $12 \mathrm{~mm}$ of embryo the EIA further progresses into the common femoral CFA and SFA. In the normal evolution, the SFA extends in the caudal direction to the level of the knee where it bifurcates into the medial descending-geniculate and superior communicating-ramus-artery. By the 22-mm stage the femoro-popliteal connection becomes the dominant blood supply to the lower extremities and continuity of SA is arrested [2].

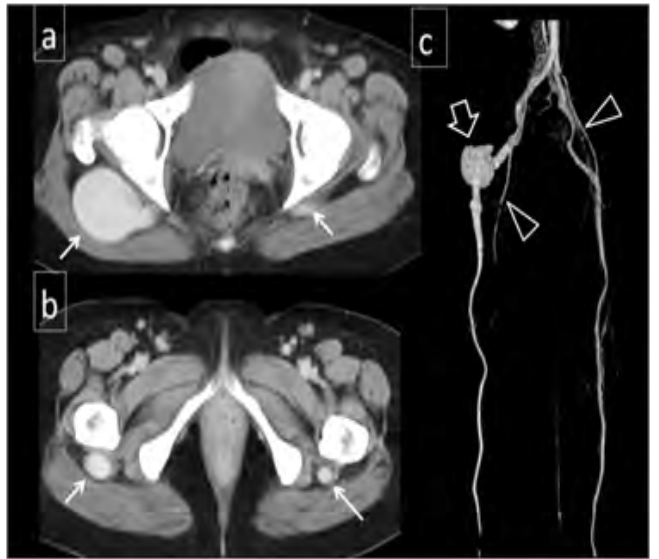

Figure 1: Axial contrast enhanced arterial phase CT demonstrate bilateral sciatic arteries (arrows) [a and b] and a large aneurysm on right side. Relatively small femoral arteries noted in the groin (triangle). 3D CT angiogram shows variant arterial anatomy and right sciatic artery aneurysm (c) (open) arrow.

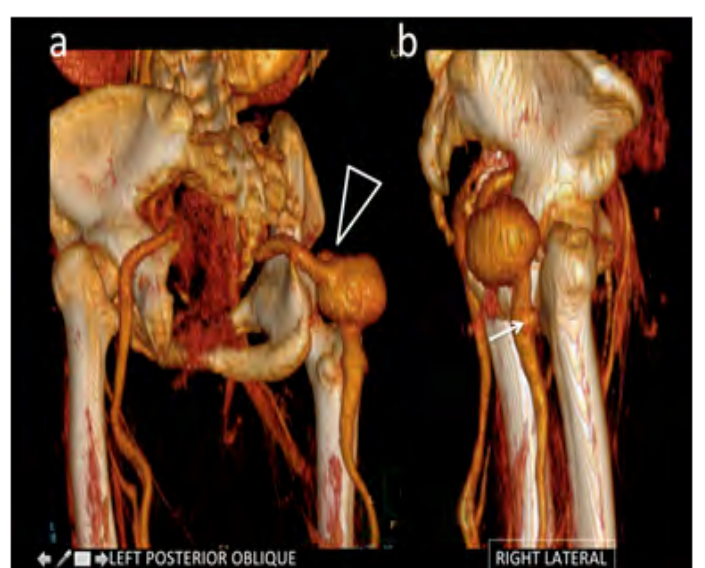

Figure 2: Surface rendered 3D reconstructions highlighting the arterial contours. Small superior outpouching (triangle) in the aneurysm (a) and an additional small aneurysm more distally (b) \{arrow\}.

There are two types of persistent-sciatic-artery; the incomplete type where there is a hypoplastic persistent-sciatic-artery along with the dominant superficial-femoral vessel and a complete type in which a dominant persistent-sciatic-artery is noted along with a hypoplastic superficial-femoral system [2]. Though PSA is a rare entity, it is clinically significant congenital anatomical variant due to diagnostic challenges and associated complications. Some earlier study reported approximately $80 \%$ of PSA as complete type [3], however recent review suggest most common type as incomplete type (Class III Ahn Min classification) [4]. There are three factors influencing management of the patient: Clinical features, aneurysm formation and the PSA type [3]. PSA has a reported incidence of 1 in 1700 to 3300. PSA's may be complicated by aneurysms (40-61\%), stenosis (7\%) and or occlusions $(9 \%)$. Aneurysm complicated PSA's are symptomatic in roughly $50 \%$ of the cases. The average age of presentation is 57 years and it harbours no gender predilection. Bilaterality has been reported in between $26.3-50 \%$ of the cases [4-6].

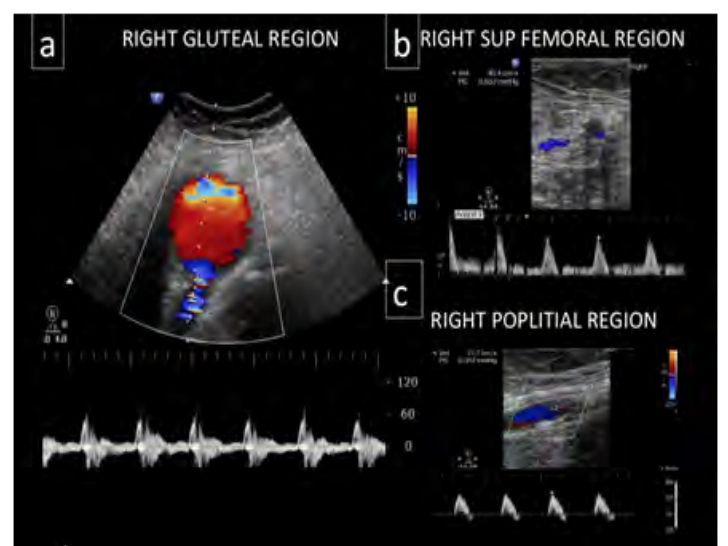

Figure 3: (a) color Doppler examination of right gluteal region shows a persistent sciatic artery and an adjacent aneurysm demonstrating a slow swirling flow. (b) Monophasic flow was note in a small caliber distal SFA. (c) Popliteal artery is normal in calibre shows biphasic flow.

In 1977, Bower et al., [2] proposed a classification system for PSA. Pillet et al., (1980) further stratified the Bower classification, subdividing PSA's into 4 types. Types 1 and 2 are complete but differ in the degree of femoral artery development. Types 3 and 4 are incomplete, in both cases the SFA is patent shows continuation with the popliteal-artery. However in type 3 the proximal portion of the PSA remains while the distal portion of the PSA remains in type 4 $[2,7]$. Classifications are further modified by Gauffree (1-5 categories) and Ahm-Min (I-IV classes) based on precise state development of contributing arteries [4].

Single noninvasive imaging modality most useful for deliniation of complex vascular anatomy is contrast enhanced CT angiography $[4,8]$. However in many clinical set ups sonography remains as an initial imaging tool. Thus familiary of unusual vascular anatomy need to be kept in mind, when cluster of observations lead to logical conclusion of possible vascular anomaly. In our case initial impression was that of narrowing SFA leading to partial occlusion, despite the demonstration of normal size and flow in popliteal artery. In relatively young patients, without known predisposing causes of vascular disease, a vascular anomaly could be considered as an additional possibility. Sonographic evaluation in suspicious cases should be extended to include gluteal region. Apart from demonstrating vascular anatomy, sonography additionally demonstrates vascular thrombosis, vascular ectasia or an aneurysm. Occasionally relation of the vascular structures to sciatic nerve can be shown confirming clinically suspected nerve compression.

Lesions due to PSA and related complications can be adequately dealt by surgical and endovascular intervention. Though some cases 
Citation: Venkatesh V, Doddabasappa G, Bhat V (2020) Persistent Sciatic Artery Presenting with Right Lower Limb Ischemia: A Potential Sonographic Pitfall. J Non Invasive Vasc Invest 5: 027.

of PSA aneurysm managed conservatively with warfarin, a definitive surgical intervention should be undertaken before severe complication sets in [8]. In complete type of PSA aneurysm vascular supply of the lower limb is almost completely dependent on this aberrant artery [9]. Vascular reconstruction procedure like Femoropopliteal bypass is a recommended method as the risk of graft compression is less common $[4,8,9]$. The aneurysm can then be dealt with gelfoam or coil embolisation. An incomplete type of PSA aneurysm is satisfactorily managed by stenting or embolisation of the aneurysm [8].

\section{References}

1. Kesri G, Mangtani J, Kumar G, Dangayach KK (2014) Persistent Sciatic Artery Aneurysm with Lower Limb Ischemia. Case Reports in Vascular Medicine 183969.

2. Bower EB, Smullens SN, Parke WW (1977) Clinical aspects of persistent sciatic artery: Report of two cases and review of the literature. Surgery 81: 588-595.

3. Morisaki K, Yamaoka T, Iwasa K, Kuma S, Okazaki J (2017) Persistent Sciatic Artery Aneurysm with Limb Ischemia: A Report of Two Cases, Ann Vasc Dis 10: 44-47.
4. Ahn S, Min SK, Min SI, Ha J, Jung IM, et al. (2016) Treatment Strategy for Persistent Sciatic Artery and Novel Classification Reflecting Anatomic Status. Eur J Vasc Endovasc Surg 52: 360-369.

5. Wu HY, Yang YJ, Lai CH, Roan JN, Luo CY, et al. (2007) Bilateral persistent sciatic arteries complicated with acute left lower limb ischemia. J Formos Med Assoc 106: 1038-1042.

6. Wang B, Liu Z, Shen L (2011) Bilateral persistent sciatic arteries complicated with chronic lower limb ischemia. Int J Surg Case Rep 2: 309-312.

7. Pillet J, Albaret P, Toulemonde JL, Cronier P, Raimbeau G, et al. [Ischio-popliteal artery trunk, persistence of the axial artery]. Bull Assoc Anat (Nancy) 64: 97-110.

8. Fung HS, Lau S, Chan MK, Tang KW, Cheung YL, et al. (2008) Persistent sciatic artery complicated by aneurysm formation and thrombosis. Hong Kong Med J 14: 492-494.

9. Mayschak DT, Flye MW (1984) Treatment of the persistent sciatic artery. Ann Surg 199: 69-74. 


\section{di \\ нетан}

Advances In Industrial Biotechnology | ISSN: 2639-5665

Advances In Microbiology Research | ISSN: 2689-694X

Archives Of Surgery And Surgical Education | ISSN: 2689-3126

Archives Of Urology

Archives Of Zoological Studies | ISSN: 2640-7779

Current Trends Medical And Biological Engineering

International Journal Of Case Reports And Therapeutic Studies | ISSN: 2689-310X

Journal Of Addiction \& Addictive Disorders | ISSN: 2578-7276

Journal Of Agronomy \& Agricultural Science | ISSN: 2689-8292

Journal Of AIDS Clinical Research \& STDs | ISSN: 2572-7370

Journal Of Alcoholism Drug Abuse \& Substance Dependence | ISSN: 2572-9594

Journal Of Allergy Disorders \& Therapy | ISSN: 2470-749X

Journal Of Alternative Complementary \& Integrative Medicine | ISSN: 2470-7562

Journal Of Alzheimers \& Neurodegenerative Diseases | ISSN: 2572-9608

Journal Of Anesthesia \& Clinical Care | ISSN: 2378-8879

Journal Of Angiology \& Vascular Surgery | ISSN: 2572-7397

Journal Of Animal Research \& Veterinary Science | ISSN: 2639-3751

Journal Of Aquaculture \& Fisheries | ISSN: 2576-5523

Journal Of Atmospheric \& Earth Sciences | ISSN: 2689-8780

Journal Of Biotech Research \& Biochemistry

Journal Of Brain \& Neuroscience Research

Journal Of Cancer Biology \& Treatment | ISSN: 2470-7546

Journal Of Cardiology Study \& Research | ISSN: 2640-768X

Journal Of Cell Biology \& Cell Metabolism | ISSN: 2381-1943

Journal Of Clinical Dermatology \& Therapy | ISSN: 2378-8771

Journal Of Clinical Immunology \& Immunotherapy | ISSN: 2378-8844

Journal Of Clinical Studies \& Medical Case Reports | ISSN: 2378-8801

Journal Of Community Medicine \& Public Health Care | ISSN: 2381-1978

Journal Of Cytology \& Tissue Biology | ISSN: 2378-9107

Journal Of Dairy Research \& Technology | ISSN: 2688-9315

Journal Of Dentistry Oral Health \& Cosmesis | ISSN: 2473-6783

Journal Of Diabetes \& Metabolic Disorders | ISSN: 2381-201X

Journal Of Emergency Medicine Trauma \& Surgical Care | ISSN: 2378-8798

Journal Of Environmental Science Current Research | ISSN: 2643-5020

Journal Of Food Science \& Nutrition | ISSN: 2470-1076

Journal Of Forensic Legal \& Investigative Sciences | ISSN: 2473-733X

Journal Of Gastroenterology \& Hepatology Research | ISSN: 2574-2566
Journal Of Genetics \& Genomic Sciences | ISSN: 2574-2485

Journal Of Gerontology \& Geriatric Medicine | ISSN: 2381-8662

Journal Of Hematology Blood Transfusion \& Disorders | ISSN: 2572-2999

Journal Of Hospice \& Palliative Medical Care

Journal Of Human Endocrinology | ISSN: 2572-9640

Journal Of Infectious \& Non Infectious Diseases | ISSN: 2381-8654

Journal Of Internal Medicine \& Primary Healthcare | ISSN: 2574-2493

Journal Of Light \& Laser Current Trends

Journal Of Medicine Study \& Research | ISSN: 2639-5657

Journal Of Modern Chemical Sciences

Journal Of Nanotechnology Nanomedicine \& Nanobiotechnology | ISSN: 2381-2044

Journal Of Neonatology \& Clinical Pediatrics | ISSN: 2378-878X

Journal Of Nephrology \& Renal Therapy | ISSN: 2473-7313

Journal Of Non Invasive Vascular Investigation | ISSN: 2572-7400

Journal Of Nuclear Medicine Radiology \& Radiation Therapy | ISSN: 2572-7419

Journal Of Obesity \& Weight Loss | ISSN: 2473-7372

Journal Of Ophthalmology \& Clinical Research | ISSN: 2378-8887

Journal Of Orthopedic Research \& Physiotherapy | ISSN: 2381-2052

Journal Of Otolaryngology Head \& Neck Surgery | ISSN: 2573-010X

Journal Of Pathology Clinical \& Medical Research

Journal Of Pharmacology Pharmaceutics \& Pharmacovigilance | ISSN: 2639-5649

Journal Of Physical Medicine Rehabilitation \& Disabilities | ISSN: 2381-8670

Journal Of Plant Science Current Research | ISSN: 2639-3743

Journal Of Practical \& Professional Nursing | ISSN: 2639-5681

Journal Of Protein Research \& Bioinformatics

Journal Of Psychiatry Depression \& Anxiety | ISSN: 2573-0150

Journal Of Pulmonary Medicine \& Respiratory Research | ISSN: 2573-0177

Journal Of Reproductive Medicine Gynaecology \& Obstetrics | ISSN: 2574-2574

Journal Of Stem Cells Research Development \& Therapy | ISSN: 2381-2060

Journal Of Surgery Current Trends \& Innovations | ISSN: 2578-7284

Journal Of Toxicology Current Research | ISSN: 2639-3735

Journal Of Translational Science And Research

Journal Of Vaccines Research \& Vaccination | ISSN: 2573-0193

Journal Of Virology \& Antivirals

Sports Medicine And Injury Care Journal | ISSN: 2689-8829

Trends In Anatomy \& Physiology | ISSN: 2640-7752

Submit Your Manuscript: https://www.heraldopenaccess.us/submit-manuscript 